\title{
Can a connectionist model explain the processing of regularly and irregularly inflected words in German as LI and L2?
}

International Journal of Bilingualism 15(4) 446-465

(C) The Author(s) 2011 Reprints and permission: sagepub.co.uk/journalsPermissions.nav DOI: 10.1 |77/|3670069||403205 ljb.sagepub.com

\section{Tilo Strobach}

Ludwig-Maximilians-University Munich; Humboldt University Berlin; Free University Berlin, Germany

\section{Ute Schönpflug}

Free University Berlin, Germany

\begin{abstract}
The connectionist model is a prevailing model of the structure and functioning of the cognitive system of the processing of morphology. According to this model, the morphology of regularly and irregularly inflected words (e.g., verb participles and noun plurals) is processed in the same cognitive network. A validation of the connectionist model of the processing of morphology in German as L2 has yet to be achieved. To investigate L2-specific aspects, we compared a group of LI speakers of German with speakers of German as L2. L2 and LI speakers of German were assigned to their respective group by their reaction times in picture naming prior to the central task. The reaction times in the lexical decision task of verb participles and noun plurals were largely consistent with the assumption of the connectionist model. Interestingly, speakers of German as L2 showed a specific advantage for irregular compared with regular verb participles.
\end{abstract}

\section{Keywords}

connectionist models, German as L2, lexical decision task, morphological regularity

\section{Introduction}

The cognitive processes involved in the comprehension and production of regular and irregular morphological word inflections have been debated intensively in terms of native speakers (e.g., Clahsen, 1999; Marcus, Brinkmann, Clahsen, Wiese, \& Pinker, 1995; Rumelhart \& McClelland, 1986) and second language (L2) learners (e.g., Grainger \& Dijkstra, 1992; Ullman, 2004). Regular inflections of the English verb participles, for instance, include the past tense ending -ed (e.g., change - changed) and irregular inflections include unique past tense changes (e.g., spend - spent,

\section{Corresponding author:}

Tilo Strobach, Department of Psychology, Ludwig-Maximilians-University Munich, Leopoldstr. I3, 80802 Munich, Germany Email: tilo.strobach@psy.Imu.de 
go - went). One prevailing model explaining the nature of the cognitive mechanisms underlying the processing of regularly and irregularly inflected words is the connectionist model (e.g., Joanisse \& Seidenberg, 1999; McClelland \& Patterson, 2002; Rumelhart \& McClelland, 1986, for an alternative view see e.g., Pinker, 1999; Pinker \& Ullman, 2002). This model postulates a network of phonological, orthographic and semantic representations of both word forms in patterns of interconnected simple processing units. In the connectionist model, it is important to stress that regular and irregular words are processed within a single network while alternative models assume different processing networks for these representations (e.g., dual-mechanism model; Pinker, 1999, see the Discussion section later in this article). Thus, the underlying cognitive architecture to process regular and irregular word forms is identical. In general, the connectionist model is part of a broader view in which cognitive processes are seen as graded, probabilistic, interactive, context-sensitive and domain-general (McClelland \& Patterson, 2002).

Empirical evidence for the connectionist model of the processing of morphology was provided by priming studies including native speakers of German (e.g., Smolka, Rösler, \& Wiese, 2003; Smolka, Zwitserlood, \& Rösler, 2007), Italian (Orsolini \& Marslen-Wilson, 1997) and French (Meunier \& Marslen-Wilson, 2004), language acquisition during childhood (Brown, 1973; Maratsos, 2000; McClelland \& Patterson, 2002), data from brain-damaged individuals (Faroqi-Shah, 2007), ERP-studies (e.g., Justus, Larsen, de Morney Davies, \& Swick, 2008), and studies investigating the influence of semantic associations on the processing of morphology (Ramscar, 2002).

However, evidence that supports the connectionist model involved in the processing of regularly and irregularly inflected words in German as L2 is still lacking. German is of particular interest here because the regular forms of verb participles (e.g., Meier, 1964) and more strongly of noun plurals (e.g., Pfeffer, 1964) occur less frequently than irregular forms (see also Marcus et al., 1995). In general, we aim to achieve a better understanding of the processing of morphemes by investigating German as L2 and as L1 in our study. Therefore, the aim of the present study is to look for evidence for a single connectionist mechanism underlying the processing of two types of regular and irregular word inflections, verb participles and noun plurals, in German, in a group of adult L2 learners when compared to German native speakers.

Recently, Smolka et al. (2007) provided evidence for the connectionist model to explain the processing of regular and irregular inflections of verb participles in German native speakers. The authors measured the amount of facilitation that regular and irregular verb participles exerted on the recognition of the related infinitive verb form in a priming paradigm. Importantly, regularly and irregularly inflected participles were controlled for confounding variables, carefully matched for lemma frequency, number of letters and neighbours (i.e., the number of words that differ by only one letter with respect to the infinitive verb form). As regular and irregular verb processing underlie the identical single network according to the connectionist model, equal priming effects were predicted for both types of verb participles. Consistent with this prediction, Smolka et al. showed that regularly inflected participles primed their infinitive verb forms to the same degree as irregularly inflected participles.

In a neuropsychological study using event-related potentials (ERP), Justus et al. (2008) investigated the time course and scalp distribution of the processing of infinitive verb forms primed by their related participles in native speakers of English. Primes for infinitive verb forms were the related regularly inflected participles (which are generated with a regular -ed ending, e.g., pack packed), weak irregularly inflected participles (which are similar to regularly inflected participles without stem changes, e.g., spend - spent) and strong irregularly inflected participles (which are truly irregular participles including stem changes, e.g., speak - spoken). Results showed a reduced N400 ERP component in trials with priming of strong irregular compared to priming of regular and 
weak irregular participles. Thus, the findings provide no evidence for a basic difference between regular and irregular participles. The differences between regularly and irregularly inflected words are rather gradual, a basic assumption of the single network system of regular and irregular inflections in the connectionist model.

\section{I.I Formation of verb participles and noun plurals in German}

In this section, we briefly summarize the formation of verb participles and noun plurals in German to enable a better evaluation of the effects to be reported in this study. Regular inflection of verb participles involves the affix $g e$ - and the suffix - $t$ without stem changes (e.g., trennen ['to separate', infinitive form] - trennte [past tense] - getrennt [past participle]). Word forms of irregular past participles are also generated with the affix ge- but, instead of the suffix - $t$, they have the suffix -en (e.g., hauen ['to hit', infinitive form] - haute [past tense] - gehauen [past participle]). Additionally, irregular participle forms might undergo unpredictable phonological stem changes for a learner of German (e.g., gehen ['to walk', infinitive form] - ging [past tense] - gegangen [past participle]; schreiben ['to write', infinitive form] - schrieb [past tense] - geschrieben [past participle]). Depending on the size of text samples used to estimate verb frequency in German, the type frequency of strong irregularly inflected verbs ranged from $16 \%$ to $68 \%$, the proportion of weak irregularly inflected verbs ranged from $1 \%$ to $31 \%$, and the proportion of regularly inflected verbs ranged from $23 \%$ to $78 \%$ (Marcus et al., 1995).

Plural formation of nouns in German consists of five categories: four categories have the plural suffixes -e (e.g., Stein, 'stone' - Steine, 'stones'), -er (e.g., Gesicht, 'face' - Gesichter, 'faces'), -[e] $n$ (e.g., Frau, 'woman' - Frauen, 'women') as well as -s (e.g., Hotel, 'hotel' - Hotels, 'hotels'), and one category is unmarked (e.g., Schüler, 'student' - Schüler, 'students'). Some plural forms in the categories with -e and -er plural suffixes co-occur with stem changes (e.g., Blatt, 'leaf' - Blätter, 'leaves'). Forms generated with $-s$ endings act as the regular default, and the remaining categories were seen as the irregular forms of plural generation (e.g., Clahsen, 1999; Marcus et al., 1995; but see also McClelland \& Patterson, 2002). Depending on the type of analysis, the type frequency of nouns taking regular $-s$ endings ranged from $0 \%$ to $9 \%$ while the remaining nouns take irregular endings (Marcus et al., 1995).

To our knowledge, there are only a few studies focusing on the cognitive processing system of regulars and irregulars in L2 learners of German. In detail, Hahne, Mueller, \& Clahsen (2006) looked at the generalization properties of regular and irregular participles (i.e., $-t$ ending vs. $-n$ ending) as well as of regular and irregular noun plurals (i.e., $-s$ ending vs. $-n$ endings) in learners with Russian as L1. That is, the authors analysed the amount of generalization of regular and irregular inflections during the production of nonce words (see also Clahsen, 1997). For participles, Hahne et al. found higher generalization rates in regular participles than in irregular participles. Investigating generalization rates of nouns, no differences in the regular and irregular plurals were found. While the data of plural generalization rather supports a single-mechanism hypothesis, the data of participle generalization showed no support for this view. Thus, evidence from the generalization data supporting a single processing mechanism within the framework of the connectionist model can be considered inconclusive at best. Furthermore, several critical issues may be raised with regard to the Hahne et al. study. First, there is no direct comparison with a control group of native speakers of German that allows an unequivocal interpretation of the results as being due to the German language or being specific to German as L2. Second, the instructed generalization task required very complex processing including multiple processing stages (e.g., for generalization of participles: (1) presentation of a simple past form, (2) repetition of a simple past form and (3) 
generating the participle form). This method only allows the assessment of frequency data but no processing of time data, which might be more sensitive to the effects of specific cognitive processes. Finally, the study of Hahne et al. leaves open the question of how L2 learners process wellformed irregular and regular word forms.

In regard of these issues, Neubauer and Clahsen (2009) applied the alternative lexical decision task (LDT) to assess processing of regularly and irregularly inflected participles in L2 learners of German (with Polish as L1) and German native speakers. The LDT asks participants to decide whether a visually presented letter string is a word or a non-word (e.g., Meyer \& Schvaneveldt, 1971). Latencies as well as error rates of the participants' decisions are recorded. The letter strings are either correct words or pseudowords (i.e., nonsense letter strings). A large number of studies reported effects of word frequency on the latencies in LDTs (e.g., Forster \& Chambers, 1973) in English, French, or Italian (Johnston \& Barry, 2006), with high frequency words processed faster than low frequency words, since high frequency words are accessed faster in a processing network than low frequency words (e.g., Rubenstein, Garfield, \& Millikan, 1970). This faster processing might result from the higher level of automatization for highly frequent words compared to infrequent words (DeKeyser, 2001; Segalowitz, 2003).

The findings of Neubauer and Clahsen (2009) showed a similar frequency effect in regular and irregular participles in the L2 learners of German providing no evidence for a basic difference between their regular and irregular participle processing. In contrast to the L2 learners' data, native speakers of German demonstrated a frequency effect for irregular participles and no frequency effect for regular participles. These group differences might be explained with a selectively reduced sensitivity for memory representations of these word forms in the native speakers compared to L2 learners. Hence, the L2 learners' findings provide evidence for a single network to process both regular and irregular participles as predicted by the connectionist model. In contrast, there is no evidence for this single processing network in the data of the native speakers.

However, Neubauer and Clahsen (2009) exclusively investigate participles but no noun plurals to provide generalizations of their findings. Furthermore, one fact that might obscure the data analyses of the LDT could be a bias towards categorizing non-words incorrectly as words in the native speakers of German and the L2 learners of German, in other words showing a 'correct' bias or false alarms (Beeckmans, Eyckmans, Janssens, Dufranne, \& Van de Velde, 2001; Mochida \& Harrington, 2006). As the authors provide no such analysis of false alarms when investigating verb participles, their findings in the native speakers and L2 learners of German are not equivocal. Additionally, L2 learners had been living in Germany, with a mean of 2;9 years and a standard deviation of 2;2 years. This relatively large deviation might result in a heterogeneous group of L2 learners in that study; thus, supplementary investigations with other task situations are needed (Neubauer \& Clahsen, 2009).

\section{The present study}

In the present study, we aimed to clarify possible cognitive mechanisms underlying the processing of regular and irregular word forms, in our case verb participles as well as noun plurals in L2 learners of German with English as L1 as compared to German native speakers. The comparison of the performance of the L2 learners and the native speakers allowed possible mechanisms of regularity processing specific to German as L2 as compared to German as L1 to be identified. The sample of L2 learners of German had been residing in Germany for at least five years. This constraint was introduced to enable the examination of a rather homogeneous sample of learners with advanced competence of German as L2 (Birdsong, 2004). 
To investigate regular and irregular word processing we applied the LDT in the present study. In particular, we presented irregular and regular verb participles and noun plurals of highly frequent and infrequent forms in this task. What are the predicted outcomes of regularly and irregularly inflected verb participles and noun plurals with high and low frequency in L2 learners in the LDT according to the connectionist model? Word frequency is expected to have a differential effect on reaction times (RTs) and error rates: low frequency regular and irregular forms are expected to result in longer RTs and higher error rates; this results from a higher level of processing automatization of words applied with a high frequency (e.g., DeKeyser, 2001). This effect in the infrequent words should be more pronounced in L2 speakers as compared to L1 speakers (Hypothesis 1), as the less frequent use of these word forms results in a lower level of proficiency particularly in the L2 learners than the same word forms for L1 speakers (Birdsong \& Flege, 2001). This is because we expect a selectively lower level of automatization when processing low frequency word forms in the former sample. Most importantly, as regularly and irregularly inflected word forms are processed in the identical cognitive network according to the connectionist model, the strength of the frequency effect should be similar in regular and irregular inflected words (Hypothesis 2). We predict that regularly inflected vs. irregularly inflected word forms similarly influence RTs and error rates for L2 learners as well as for native speakers of German: hence, we assume no processing of morphology specific to L2 (Hypothesis 3). Finally, we expect the interaction of frequency and language of speakers (i.e., L1 vs. L2; Hypothesis 1) should have no differential effect on regularly vs. irregularly inflected words (Hypothesis 4). We stress at this point that the predictions are expected to be equivalent for verb participles and noun plurals.

\section{Methods}

Participants. The sample is described in Table 1. It included 13 L2 learners of German with English as L1 (8 females) who grew up in families with English as L1 outside of Germany. Six L2 learners grew up in the USA, five in the UK, one in the Philippines and one in New Zealand. The mean age of the participants was $M=32.3$ years ( $S D=8.9$ years) with a range from 23 to 53 years. The average age of arrival in Germany was $M=21.2$ years $(S D=4.7$ years) ranging from 10 to 28 years. Hence, the average number of years of residence in Germany was $M=11.2$ years $(S D=8.2$ years $)$ ranging from 5 to 30 years. Eight L2 learners had acquired no additional language before German. Two L2 learners started with French, two with Spanish and one with Chinese before they began to acquire German. The sample contained 12 right-handed and one left-handed participant assessed with the Edinburgh Handedness Test (Oldfield, 1971). The participants were either university students or they had already finished studying at the time of testing. At this point, the average numbers of university semesters was $M=7.8(S D=5.6)$, and the range was from 1 to 22 semesters.

The sample of native speakers of German contained 15 undergraduates from the Free University of Berlin (10 females). All were born in Germany and grew up in German-speaking families. The mean age was $M=22.2$ years $(S D=2.8$ years) with a range from 20 to 31 years. Whereas English was L2 for 14 participants, the remaining one participant had Russian as L2 but had learned English as L3. The sample contained 14 right-handed participants and one left-handed participant. The mean number of university semesters was $M=3.7(S D=2.7)$ with a range from 1 to 11 . This group of students did not study the English language or use English as a means of communication in their curriculum.

Participants in both groups had normal or corrected-to-normal vision, and were naïve to the purpose of the experiment. They were recruited via personal contacts or through flyers posted in campus buildings. Participants did not receive any remuneration for their participation. 
Table I. Sociodemographic data of the research samples

\begin{tabular}{|c|c|c|}
\hline & German as L2 learners & Native speakers of German \\
\hline Age (in years) * & $32.3(2.5)$ & $22.6(0.8)$ \\
\hline$N$ subjects & 13 (8 females) & I5 (I0 females) \\
\hline Years of residence in Germany* & $11.2(2.3)$ & $22.2(0.7)$ \\
\hline Years of residence outside of Germany * & $19.9(1.6)$ & $0.4(0.1)$ \\
\hline Age upon arrival in Germany* & $21.2(1.3)$ & 0.0 \\
\hline Semester at university $*$ & $7.8(1.5)$ & $3.7(0.7)$ \\
\hline $\begin{array}{l}\text { Self-rated L2 competence } \\
\text { (I-4 points) }\end{array}$ & L2 German & L2 English \\
\hline Speaking * & $2.9(0.2)$ & $2.0(0.1)$ \\
\hline Writing & $2.1(0.3)$ & $2.1(0.2)$ \\
\hline Reading $*$ & $3.2(0.2)$ & $2.1(0.2)$ \\
\hline Listening comprehension * & $3.3(0.1)$ & $2.5(0.2)$ \\
\hline \multicolumn{3}{|l|}{ Picture naming latencies in $\mathrm{ms}$} \\
\hline In English * & 1423 (159) & $1700(|8|)$ \\
\hline In German * & 1506 (I53) & I335 (| 86$)$ \\
\hline Difference $(\mathrm{L} 2-\mathrm{LI}) *$ & $83(124)$ & $365(178)$ \\
\hline
\end{tabular}

* Significant differences between categories at $p<.05$.

Similar to previous studies with late bilinguals, we selected groups of participants based on their language learning biography (e.g., MacKay, James \& Abrams, 2002). However, it is unclear whether these data provide sufficient information about the L1 and L2 competence. To validate empirically our group assignments to groups of native speakers and L2 learners based on the biographical data, we introduced an additional picture-naming (PN) test to assess the dominance of either L1 or L2 in both groups of participants. Additionally, we asked participants for a self-rated L2 proficiency.

PN test. In the PN test, participants were instructed to name pictures visually presented (e.g., Jared \& Kroll, 2001; Meuter \& Allport, 1999) alternately in English or in German (for methods see Appendix A). We predicted that participants would show longer naming times in their second as opposed to their first language (Jared \& Kroll, 2001). According to Meuter and Allport (1999), we assume that this difference is increased in the German native speakers when compared to the L2 learners of German. This increased difference might result from the enlarged dominance of German compared to English (in the German native speakers) than the dominance of English compared to German (in the L2 learners).

The results of the PN test showed that participants responded with an incorrect word in only $0.3 \%$ of the trials (i.e., false response language or incorrect words) and missed responses in $0.4 \%$ of the trials, resulting in overall error rates of $0.7 \%$. Due to the low value, no inference statistics were applied to the error rates. Prior to the RT analysis, erroneous trials were rejected from the further analysis. We included the within-subject factor response language (English vs. German) and the between-subject factor language group (German L1 speaker vs. L2 learners) into a $2 \times 2$ mixed measures ANOVA with participants as the random variable. The analysis revealed a main effect of response language, $F(1,26)=22.927, p<.001, \eta p^{2}=.469$. Names produced in German showed faster RTs $(1421 \mathrm{~ms})$ than names produced in English $(1,562 \mathrm{~ms})$. The interaction of response language and language group was significant, $F(1,26)=58.002, p<.001, \eta p^{2}=.690$. As presented in Table 1, both German native speakers and L2 learners showed faster RTs in their L1. The time difference between English and German naming was significant in German natives $(p<$ 
$.001)$, but was only marginally significant in the L2 learners $(p>.06)$, thus revealing the German native speakers' strong German dominance and the L2 learners' greater balance in competencies in the two languages. The factor language group had no significant effect. Thus, the picture-naming RTs in English and in German in the L2 learners and the native speakers of German validated the selection of groups of participants based on their language learning biography.

Self-rated L2 proficiency. The L2 learners of German with English as L1 and the native speakers of German rated their L2 proficiency (i.e., L2 learners in German, native German speakers in English) with regard to speaking, writing, reading and oral comprehension in a paper-and-pencil test. Ratings were conducted on a four-point scale from 1 (very low proficiency) to 4 (very high proficiency). The results of the self-rated L2 proficiency in speaking, writing, reading and oral comprehension showed that the L2 learners rated their German L2 proficiency significantly higher in speaking $(p<.001)$, reading $(p<.001)$ and oral comprehension $(p<.01)$, but not in writing compared to the English proficiency of the German native speakers (see Table 1). These findings again supported our group selection based on the language learning biography.

Apparatus and stimuli. During the LDT, participants were instructed to decide whether a letter string presented on the screen is a word or a non-word. The LDT was presented on an LCD screen of 17 inches and controlled by PsyScope 1.2.5 PPC (Cohen, MacWhinney, Flatt, \& Provost, 1993) on an iMac G5 of Apple with Mac OS X (Version 10.3.5). The screen had a resolution of $1140 \times$ 900 pixels. All word forms were presented in Chicago font with font size 32 on the screen.

The list of stimuli presented in the LDT on verb participles is given in Appendix B. We selected 10 highly frequent regular (e.g., gemacht, "done") and 10 highly frequent irregular (e.g., geschrieben, "written") participle forms. In addition, 10 low frequency regular (e.g., gewacht, "kept watch") and 10 low frequency irregular (e.g., geritten, "ridden") participle forms were selected. Six of the frequent and five of the infrequent irregular forms undergo a stem change. Frequency was determined by the absolute number of occurrences in the selected text corpus of a vocabulary database (Projekt Deutscher Wortschatz, n.d. [www.dict.uni-leipzig.de]). Participles of high frequency ranged from a frequency of 5005 to 62,309 ( $M$ [regular] $=20,816.5, S D$ [regular] $=$ $16,440.0] ; M[$ irregular $]=17,703.7, S D$ [irregular $]=10,908.6, p>.70)$. Infrequent participles had a frequency between 16 and $495(M[$ regular $]=247.9, S D$ [regular] $=154.5 ; M[$ irregular $]=266.6$, $S D$ [irregular $]=167.6, p>.36$ ). Word length of all selected verb participles ranged from 5 to 11 letters. A repeated measures ANOVA with the factors frequency (high frequency vs. low frequency) and regularity (regular vs. irregular) on word length showed no effect or interaction; this indicated that word length was similar in each set of verb participles.

From each selected participle, we generated one readable non-word. For regular participle inflections, non-words were generated with a suffix -en and stem change by exchanging one or two letters, mostly a vowel (e.g., gemächen, gewächen). Non-words generated from correct irregular past tense forms were generated with a suffix - $t$ but no stem change (e.g., geschreibt, gereitet).

The list of stimuli presented in the LDT on noun plurals is given in Appendix C. Regular nouns had the suffix -s (e.g., Autos "cars"), while irregular nouns had the suffixes -en (e.g., Türen "doors"), -e (e.g., Bäume "trees"), or -er (e.g., Häuser "houses"). Both groups of regular noun and irregular noun plurals consisted of 10 highly frequent and 10 infrequent forms. Highly frequent plurals ranged from a frequency of 2947 to $18,026(M$ [regular] $=6301.3, S D$ [regular] $=4402.6$; $M$ [irregular ] $=6998.3, S D$ [irregular] $=3181.6, p>.74)$ and infrequent plurals showed a frequency from 6 to $311(M[$ regular $]=122.2, S D[$ regular $]=101.2 ; M[$ irregular $]=148.5, S D[$ regular $]=103.3, p>.65)$ based on the frequency information of the word database (Projekt Deutscher Wortschatz, n.d.). 
Word length of all selected noun plurals ranged from four to nine letters. A repeated measures ANOVA with the factors frequency (high frequency vs. low frequency) and regularity (regular vs. irregular) on word length showed no effect or interaction; this indicated that word length was similar in each set of noun plurals.

From each selected noun, we generated one readable non-word. Therefore, we added either the suffixes -er, $-e$, or -en plus stem changes in some nouns in the group of regular nouns (e.g., Auter, Schäler). In the group of irregular nouns, we added the suffix $-s$ (in some cases for a better readability the suffix -se) and changed word stems via umlaut inclusion in some nouns (e.g., Türs, Bäumse, Hauss).

Experimental design. In the LDT on verb participles and noun plurals, each trial started with a blank screen of $1500 \mathrm{~ms}$. Following this, the question 'Is the word correct or incorrect?' (in German: 'Ist das ein richtiges oder falsches Wort?') appeared on the top of the screen, and "Correct" (in German: "Richtig") as well as "Incorrect" (in German "Falsch") appeared on the bottom left and right of the screen to indicate the response key assignment. After $500 \mathrm{~ms}$, a fixation cross appeared in the centre of the screen for $250 \mathrm{~ms}$. The fixation cross was replaced by a word or a non-word stimulus. This screen remained until the participants pressed one response button or a $5000 \mathrm{~ms}$ interval expired.

At the beginning of this part of the experiment, written instructions with a detailed description of the LDT were given to the participants. Thereafter, the block including the LDT on verb participles was initiated. The block started with three warm-up trials randomly selected from the stimuli presented during the following experimental trials. These trials were excluded from subsequent analyses. During the experimental trials, the 40 verb participles and the 40 non-words derived from existing verb participles were presented randomly.

Next, the test block with the LDT on noun plurals was started with an identical procedure to the previous block of the LDT on verb participles. In both blocks of the LDT, half of the participants pressed the M-key for words and the X-key for non-words on a standard computer keyboard, while for the other half, this allocation of the keys was reversed. Each block of the LDT lasted for 15 minutes.

\section{Results}

Verb participles. RTs and error rates of the LDT on verb participles are given in Figure 1 and Table 2 , respectively. RTs above and below three standard deviations from the mean and error trials were considered as outlier. Trials with outliers were discarded from the analysis, excluding $6.6 \%$ of trials in the native speakers and $8.7 \%$ in the L2 learners of German $(p>.1)$. RTs and error rates were subjected to a three-way mixed measures ANOVA with factors of frequency (low vs. high), regularity (regular vs. irregular) and native language group (native speakers of German vs. German as L2 learners) with participants as the random variable.

For RTs, a main effect of regularity, $F(1,26)=26.196, p<.001, \eta p^{2}=.502$, was found, a main effect of frequency, $F(1,26)=54.698, p<.001, \eta p^{2}=.678$, and a main effect of native language group, $F(1,26)=9.104, p<.01, \eta p^{2}=.259$. This analysis showed faster RTs for irregular than for regular verbs. Low frequency verbs were responded to more slowly than high frequency verbs, and native speakers of German were generally faster than English natives. Importantly, there was an interaction of frequency and native language group, $F(1,26)=6.200, p<.05, \eta p^{2}=.193$, reflecting the fact that the frequency effect was less prominent in native speakers of German than in German as L2 learners (Hypothesis 1). To rule out the possibility that the finding of increased frequency effects in the group of L2 learners of German compared to the German native speakers is based on only a few participants, we additionally conducted a non-parametric test on the individual frequency effect; such an influence of only a few participants is reasonable in groups of modest 


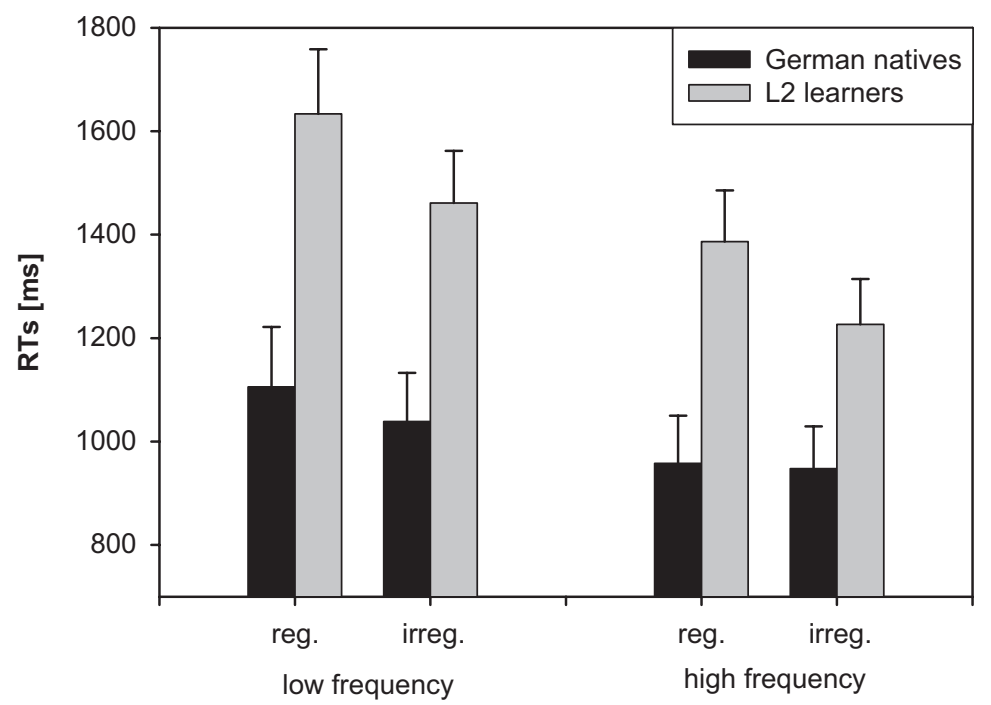

Figure I. Reaction times in ms of native speakers of German and L2 learners in the LDT with verb participles $($ reg. $=$ regular forms, irreg. $=$ irregular forms). Bars represent standard errors

Table 2. Error rates in per cent of native speakers of German and L2 learners in the LDT with verb participles and noun plurals

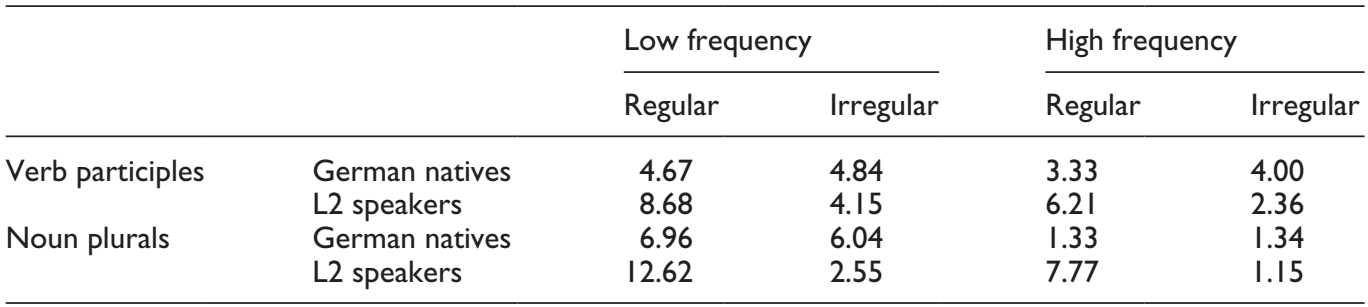

sample sizes as in the present study. The non-parametric test includes the rank of each participant according to its frequency effect and ignores the absolute magnitude of this effect. In this list, a lower rank value indicates a lower effect magnitude. A Mann-Whitney $U$ test demonstrated significantly lower list ranks for native speakers (mean rank $=11.47$ ) as compared to the L2 learners of German (mean rank $=18.00$ ), $p<.05$. This test rules out that the present findings of increased frequency effects in the L2 learners result per incidence from only a subset of participants with a strongly increased effect compared to the rest of the participants.

In contrast to the interaction of frequency and native language group, we found no interaction of regularity and frequency (Hypothesis 2), $F(1,26)<1$, as well as no 3-way interaction of regularity, frequency and language group (Hypothesis 4$), F(1,26)<1$. These findings supported the predictions of the connectionist model so far. However, there was an interaction of regularity and native language group, $F(1,26)=10.209, p<.01, \eta p^{2}=.282$. In this interaction, German as L2 learners demonstrated significantly faster RTs to irregular than to regular verbs, whereas native speakers of German showed no such difference. This particular finding was inconsistent with the 


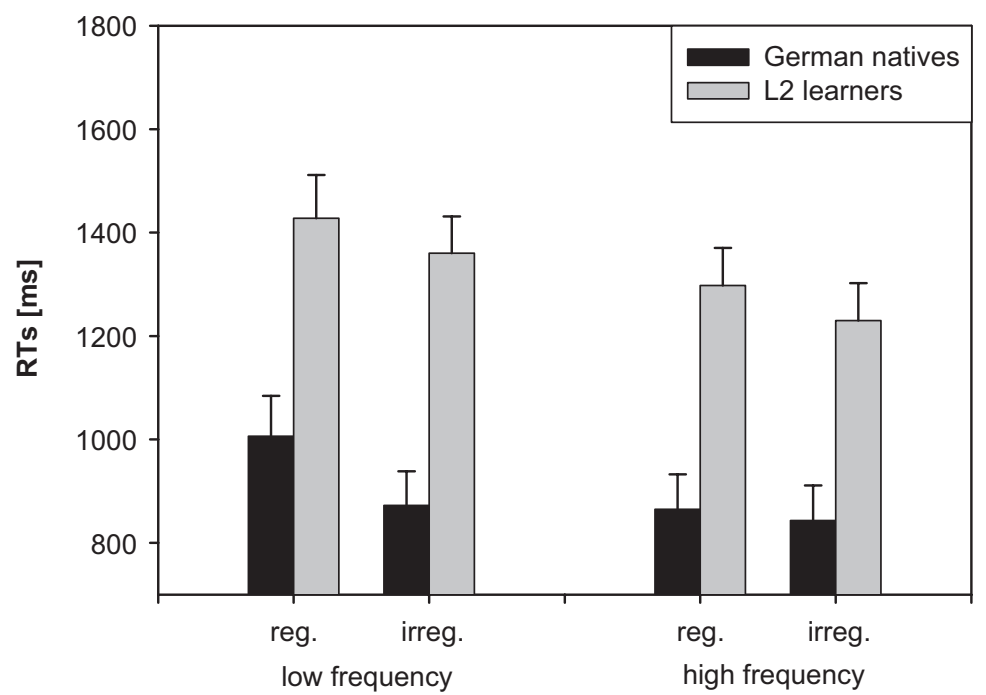

Figure 2. Reaction times in ms of native speakers of German and L2 learners in the LDT with noun plurals $($ reg. $=$ regular forms, irreg. $=$ irregular forms). Bars represent standard errors

predictions of the connectionist model. A Mann-Whitney U test demonstrated that the selective regularity effect in the L2 learners of German was not the result of strongly increased effects in a subset of participants compared with the rest of the participants. In this test, German native speakers showed lower ranks (indicating lower magnitudes of regularity effects; mean rank $=10.87$ ) than German as L2 learners (mean rank $=18.69$ ), $p<.05$.

The analysis of error rates supported the finding of non-significant interactions of regularity and frequency (Hypothesis 2), $F(1,26)<1$, and regularity, frequency, and native language group (Hypothesis 4) in the RTs, $F(1,26)<1$. However, this analysis was consistent with the RT finding of an interaction of regularity and native language group, $F(1,26)=3.773, p<.062, \eta p^{2}=.127$, indicating marginally lower error rates for irregular than for regular verbs in German as L2 learners, whereas no difference was found in native speakers of German. A Mann-Whitney U test, however, provided no evidence that the selective regularity effect in the L2 learners of German was not the result of strongly increased effects in a subset of participants compared with the rest of the participants, $p>.21$. All main effects and the interaction of frequency and native language group were not significant.

Generally, one fact that might obscure a comparison of the LDT data between different groups could be the number of false alarms, that is, categorizing non-words as words. In order to rule out this possibility, we separately analysed the error rates of the non-word responses in both the L2 learners and the German native speakers. The analyses of the incorrect verb participles, $t(26)<1$, showed no difference of the error rates (due to false alarms) between both groups of participants; thus, we assume no impact of false alarms on the present LDT analysis.

Furthermore, we separately analysed the RT and error data of the strong irregularly and the weak irregularly inflected verb participles. We found that the data of the weak irregular forms resembled those of the strong ones, $F(1,26)<1$. Note that the number of words in each category of regularity was comparatively low, and conclusions should only be drawn with caution.

Taken together, the data are consistent with the connectionist-model prediction of an increasingly pronounced frequency effect in the L2 learners; this effect was similar in regularly and 
irregularly inflected words as well as in the interaction of regularity and native language group. However, the data are inconsistent with the Hypothesis 3 that regularly inflected and irregularly inflected word forms show a similar influence on the LDT performance of L2 learners and native speakers of German. We will return to this latter finding in the Discussion section.

Noun plurals. RTs and error rates of the analysis of noun plural processing are presented in Figures 2 and Table 2, respectively. Data analyses were identical to the LDT on verb participles. RTs below and above 3 SDs from the RT means were considered as outliers and trials with outliers were discarded from the analysis. Including erroneous trials, a total of $5.6 \%$ of the trials were excluded from the data of the native speakers and a total of $9.7 \%$ of the trials were excluded from the data of the L2 learners of German $(p>.2)$.

In the RT analysis, we found a main effect of frequency, $F(1,26)=19.803, p<.001, \eta p^{2}=.432$, a main effect of regularity, $F(1,26)=10.082, p<.01, \eta p^{2}=.279$, and a main effect of native language group, $F(1,26)=20.753, p<.001, \eta p^{2}=.444$. Regular nouns showed slower RTs than irregular nouns, responses to low frequency stimuli were slower than high frequency stimuli, and native speakers of German were faster than L2 learners of German during the LDT. Neither regularity $\times$ frequency (Hypothesis 2), $F(1,26)=1.707, p>.21$, regularity $\times$ native language group (Hypothesis $3), F(1,26)<1$, as well as frequency $\times$ regularity $\times$ native language group (Hypothesis 4$), F(1,26)$ $=1.751, p>.19$, were significant. These findings supported the predictions of the connectionist model so far. However, the RT analysis provided no support for the prediction of an interaction of frequency $\times$ native language group, $F(1,26)<1$.

For error rates, marginal effects were found on regularity, $F(1,26)=4.009, p<.06, \eta p^{2}=.134$, and language group, $F(1,26)=3.871, p<.06, \eta p^{2}=.130$. That is, error rates were slightly lower in irregular than in regular noun conditions and in German as L2 learners than in native speakers of German. However, the effect of frequency was clearly significant, $F(1,26)=79.452, p<.001, \eta p^{2}$ $=.753$. Trials of high frequency nouns showed fewer errors than low frequency nouns. Importantly, the interaction of frequency and native language group was significant (Hypothesis 1), $F(1,26)=$ $4.401, p<.05, \eta p^{2}=.145$, indicated that the frequency effect was less prominent in native speakers of German than in learners of German as L2. A Mann-Whitney U test demonstrated marginally lower list ranks of the native speakers (mean rank $=11.46$ ) as compared to the L2 learners (mean rank $=17.13), p<.06$. This test is largely inconsistent with the assumption that the present findings of increased frequency effects in the L2 learners results per incidence from only a subset of participants with a strongly increased effect compared to the rest of the participants. The remaining interactions of regularity $\times$ frequency (Hypothesis 2), $F(1,26)=1.899, p>.18$, regularity $\times$ native language group (Hypothesis 3), $F(1,26)=2.203, p>.15$, as well as frequency $\times$ regularity $\times$ native language group (Hypothesis 4), $F(1,26)<1$, were not significant. These findings supported the predictions of the connectionist model.

To analyse false alarms, we compared error rates in incorrect verb participles (i.e., categorizing incorrect words as words) between native speakers and L2 learners of German. However, there was no difference in these error rates between both groups of participants, $t(26)<1$. This analysis rules out that the present LDT findings with noun plurals are obscured by a bias to consistently categorizing items as words.

In sum, the data of these analyses are largely consistent with the predictions of the connectionist model. Thus, performance RTs increased in infrequent as compared to frequent noun plurals, and increase was more prominent in the error rates of the L2 learners than of the native speakers of German. We demonstrated that regular and irregular noun plurals have a similar influence on the 
performance in trials with low and high frequency words, on the performance in both groups and on the interaction with regularity and native language group.

\section{Discussion}

The aim of the present study was to validate the connectionist model involved in the processing of regular and irregular verb participles and noun plurals in L2 learners of German compared to native speakers of German. This comparison allows the disentangling of L2-specific processing of regular and irregular word forms in German. Prior to testing, we introduced a picture-naming (PN) test to measure the basic processing speed in L1 and L2 in the L2 learners and the native speakers of German in order to validate our group selection based on the language learning biography of the participants.

Focusing on the data in the LDT, we interpret our findings as largely consistent with the predictions of the connectionist model to explain inflected word processing. In detail, Hypothesis 1 was supported when we found a generally impaired performance of the L2 learners of German as compared to German as L1 speakers, which was mainly due to increased slowing in the processing of infrequent verb participles and higher error rates in infrequent noun plurals. Additionally, regular and irregular word forms showed a similar influence on the performance of L2 learners and native speakers of German in the LDT including verb participles and noun plurals; these data supported Hypothesis 2. Additionally, we obtained an equal effect of regularly and irregularly inflected noun plurals on the performance of both groups of participants (Hypothesis 3). Hypothesis 4 (i.e., a nonsignificant interaction of regularity, frequency, and native language group) was consistently found in both data sets, the verb participles and noun plurals. These data support the interpretation that a single cognitive network underlies the processing of regularly and irregularly inflected word forms. Importantly, they show that this processing architecture is not specific for the L2 learners of German.

However, some findings in the present study were not predicted by the connectionist model. First, in all of our analyses, participants showed consistently faster RTs in trials with irregular verb participles and irregular noun plurals. This outcome seems plausible in the light of the fact that irregular forms of verb participles, and more strongly of noun plurals, occur more frequently than regular forms in German (Marcus et al., 1995). However, the finding of faster RTs in irregular word forms is surprising, as we carefully controlled for frequency in regular and irregular word forms, and selected groups of regular and irregular word forms that did not differ in frequency. It might be that the general frequency difference between irregular and regular word forms in German induces the varying RTs independently from the frequency of each individual word form. That is, this general frequency difference might have an influence on the recognition speed of word forms in the LDT in addition to the frequency of the specific word form. But how might this general effect work during recognition? We argue that the processing of the words presented on the screen during the LDT not only activates the mental representation of the actually presented word but also coactivates additional lexical representations of the same category (e.g., the presentation of regular verb participles activates several other representations of regular verb participles). This co-activation of similar alternative representations might slow down the lexical decision process, as the decision among the very similar regular verb forms requires a more fine-tuned discrimination than the differentiation among the more unusual forms of the irregular participles. This idea of co-activated representation is consistent with findings of priming studies using ambiguous speech stimuli (Marslen-Wilson, 1987).

The second finding inconsistent with Hypothesis 2 of the connectionist model was the differential influence of regular and irregular verb participles on the RTs of L2 learners of German. That is, RTs in trials of irregular verb participles were faster than RTs in trials with regular verb participles 
in the LDT task for L2 learners but not for native speakers of German in this particular analysis. We argue that regular as well as irregular word forms are highly overlearned in the native speakers of German, resulting in a high level of proficiency of word processing. This high proficiency level was associated with a high level of automatization of language processing in native speakers (e.g., DeKeyser, 2001). High levels of processing automaticity for both regular and irregular word forms might result in similar processing times of the lexical decision in the native speakers. However, L2 learners of German showed higher proficiency in the recognition of correct irregular verb participles as compared to regular verb participles. This difference might be the result of varying levels of processing automatization with lower levels in regular words and higher levels in irregular words in the L2 learners; potentially a result of formal instruction when learning regular and irregular verbs in German as L2 (Gor \& Cook, 2010). As we selected L2 learners of German who had been residing in Germany for at least five years we expected to include a sample of learners with high competence in German (Birdsong, 2004). The present results reveal that this was not the case, at least not in the domain of regularly inflected verb participles.

In contrast to the present findings of the German native speakers, Neubauer and Clahsen (2009) found frequency effects on irregular participles but not on regulars. One reason for the discrepancy between their and our findings might be the increased number of participants in Neubauer and Clahsen's study compared to the present study. In detail, Neubauer and Clahsen included 31 German native speakers and 30 L2 learners while our study included 15 German native speakers and 13 L2 learners. This may result in a significant interaction of frequency and regularity in Neubauer and Clahsen and may prevent this interaction from being significant in the present study because of reduced statistical power. However, two facts argue against an impact of the moderate sample on this study. First, non-parametric tests (see Results section) were largely inconsistent with the assumption that the present findings of different frequency or regularity effects in the L2 learners and native speakers of German results per incidence from only a subset of participants with strongly increased effects compared to the rest of participants. Second and even more important, power analyses applying G*Power (Faul, Erdfelder, Buchner, and Lang, 2009) demonstrated that sample sizes of that of Neubauer and Clahsen would not be sufficient to produce significant interactions given the present data. Thus, we assume that there is no power problem due to a smaller sample size in the present study; the differences in sample sizes thus may explain no differences between the outcomes of Neubauer and Clahsen and our study. An alternative reason for the differences between the findings might be that different numbers of items are presented in both studies (Beeckmans et al., 2001). For testing verb participles, Neubauer and Clahsen presented 36 regular and irregular participles with high and low frequency among 99 existing nouns, adjectives, alternative verbs as well as 135 non-words. In contrast, we exclusively presented 20 verb participles and 20 noun plurals among 20 novel derivates of these words in the present experiments. The inclusion of a different number of items results in different lengths of the tests which probably led to different levels of motivation and attention particularly in the native speakers of German; this might result in selective effects on regular and irregular verbs in the Neubauer and Clahsen study but not in the present study. Additionally, the different test lengths might explain the general RT difference between both studies. While mean RT across groups of participants and regular/irregular verbs was $761 \mathrm{~ms}$ in Neubauer and Clahsen, this mean RT was $1220 \mathrm{~ms}$ in the present study. This higher number of trials in the former study might lead to an unspecific effect of familiarization with the test situation and, as a result, a general reduction of RTs.

Generally, a problem with LDT is that there are no guidelines for the construction of non-words (Beeckmans et al., 2001). This also leads to problematic non-word generation in the present study: one non-word was generated in the way that only spelling but not morphology differed from the 
existing word (i.e., Haus "house" $\rightarrow$ Hauss), or exists at least in regional varieties of German (i.e., gehaut "beaten"), as well as in standard German (i.e., Schäler "peeler"). ${ }^{1}$ To rule out an impact of these problematic non-words on the data (i.e., Hauss, Schäler, gehaut) we excluded the data of the associated words in supplemental analyses (i.e., Haus, Schals, gehauen). However, the findings of these supplemental analyses (not reported in detail here) were very similar compared to the findings of the overall analyses; these findings thus argue against an impact of problematic non-word generation in the present study. Finally, the precise interpretation of frequency effects in LDT has increasingly become open to question in the literature (e.g., Järvikivi, Bertram, \& Niemi, 2006). We think, however, that this is not crucial for the present findings as these interpretations were beyond the scope of the present study.

So far, we have focused exclusively on the connectionist model to explore the cognitive mechanisms underlying the processing of regularly and irregularly inflected words. The alternative is the dual-mechanism model, in which the processing of word inflection is explained by the interconnected use of two separate processing components: the lexicon and the syntax (for reviews see Clahsen, 1999; Pinker, 1999; Pinker \& Ullman, 2002). The mental lexicon consists of a list of lexical entries specified by the membership in a syntactical category (e.g., Verb, Noun), the form, the morphological information and the meaning for each entry. The syntax, however, is a system of productive, computational, and combinatorial operations. Importantly, this model assumes different processing modes for regular and irregular inflection. While regular inflection is rather based on syntactic processing, irregular inflection is associated with the retrieval of word forms from the lexicon component.

For instance, Ullman, Corkin et al. (1997) and Ullman, Pancheva et al. (2005) provided data from a patient with anterior brain lesions and patients with Parkinson's disease, showing particularly impaired performance in regularly inflected words than in irregularly inflected words in a past-tense formation task. The authors interpreted their results as empirical evidence for a dual-mechanism model for regular and irregular inflections. However, Bird, Lambon Ralph, Seidenberg, McClelland \& Patterson (2003) showed that uncontrolled differences between regular and irregular words in the Ullman et al. studies could have influenced the results, and argued against the assumption of a dualmechanism model involved in the processing of regular and irregular word forms.

From a more general perspective, McCelland and Patterson (2002) listed findings in numerous linguistic phenomena (e.g., the acquisition sensitivity to phonology, semantics, or morphology) that were consistent with the predictions of the connectionist model but inconsistent with predictions of the dual-mechanism model. Thus, we rather assume that the dual-mechanism model is inappropriate to explain processing of regular and irregular inflections.

\section{Conclusions}

Taken together, we provide empirical evidence for the connectionist model to explain the processing of regular and irregular word inflections in L2 learners of German. For future studies, it is of interest whether the L1 of the L2 learners influences the processing of regular and irregular words forms in a different way (for an example in English as L2, see Basnight-Brown, Chen, Hua, Kostic, $\&$ Feldman, 2007). Therefore, these studies should focus on the investigation of groups of participants with different L1. Moreover, it is important to address the unusual finding of improved performance of L2 learners of German in trials with irregular verb participles while native speakers of German did not demonstrate differential RTs for regular and irregular word forms. In general, future studies are important to address possible boundary conditions of the connectionist model of processing of morphology in German and other languages as L1 and L2. 


\section{Note}

1. We thank one anonymous reviewer for this suggestion.

\section{References}

Basnight-Brown, D. M., Chen, L., Hua, S., Kostic, A., \& Feldman, L. B. (2007). Monolingual and bilingual recognition of regular and irregular english verbs: Sensitivity to form similarity varies with first language experience. Journal of Memory and Language, 57, 65-80.

Beeckmans, R., Eyckmans, J., Janssens, V., Dufranne, M., \& Van de Velde, H. (2001). Examining the Yes/ No vocabulary test: Some methodological issues in theory and practice. Language Testing, 18, 235-274.

Bird, H., Lambon Ralph, M. A., Seidenberg, M. S., McClelland, J. L., \& Patterson, K. (2003). Deficits in phonology and past-tense morphology: What's the connection? Journal of Memory and Language, 48, $502-526$.

Birdsong, D. (2004). Second language acquisition and ultimate attainment. In A. Davies, \& C. Elder (Eds.), Handbook of applied linguistics (pp. 82-105). London: Blackwell.

Birdsong, D., \& Flege, J. E. (2001). Regular-irregular dissociations in L2 acquisition of English morphology. In A. J. Do, L. Domínguez, \& A. Johansen (Eds.), Proceedings of the 25th Annual Boston University Conference on Language Development, vols 1 and 2 (pp. 123-132). Somerville, MA: Cascadilla Press.

Brown, R. (1973). A first language. Cambridge, MA: Harvard University Press.

Clahsen, H. (1997). The representations of participles in the German mental lexicon: Evidence for the dualmechanism model. In G. E. Booij, \& J. V. Marle (Eds.), Yearbook of Morphology 1996 (pp. 1-31). Dordrecht: Kluwer.

Clahsen, H. (1999). Lexical entries and rules of language: A multidisciplinary study of German inflection. Behavioral and Brain Sciences, 22, 991-1060.

Cohen, J. D., MacWhinney, B., Flatt, M., \& Provost, J. (1993). PsyScope: A new graphic interactive environment for designing psychology experiments. Behavior Research Methods, Instruments, \& Computers, $25,257-271$.

DeKeyser, R. M. (2001). Automaticity and automatization. In P. Robinson (Ed.), Cognition and second language instruction (pp. 125-151). New York: Cambridge University Press.

Faroqi-Shah, Y. (2007). Are regular and irregular verbs dissociated in non-fluent aphasia? A meta-analysis. Brain Research Bulletin, 74, 1-13.

Faul, F., Erdfelder, E., Buchner, A., \& Lang, A.-G. (2009). Statistical power analyses using G*Power 3.1: Tests for correlation and regression analyses. Behavior Research Methods, 41, 1149-1160.

Forster, K. I. F., \& Chambers, S. M. (1973). Lexical access and naming time. Journal of Verbal Learning and Verbal Behavior, 12, 627-635.

Francis, W. N., \& Kucera, H. (1982). Frequency analysis of English usage: Lexicon and grammar. Boston, MA: Houghton Mifflin.

Gor, K., \& Cook, S. (2010). Nonnative processing of verbal morphology: In search of regularity. Language Learning, 60(1), 88-126.

Grainger, J., \& Dijkstra, A. (1992). On the representation and use of language information in bilinguals. In R. J. Harris (Ed.), Cognitive processing in bilinguals (pp. 207-220). Amsterdam: Elsevier Science Publications.

Hahne, A., Mueller, J., \& Clahsen, H. (2006). Morphological processing in a second language: Behavioural and event-related potential evidence for storage and decomposition. Journal of Cognitive Neuroscience, $18,121-134$.

Jared, D., \& Kroll, J. F. (2001). Do bilinguals activate phonological representations in one or both of their languages when naming words? Journal of Memory and Language, 44, 2-31.

Järvikivi, J., Bertram, R., \& Niemi, J. (2006). Affixal salience and the processing of derivational morphology: The role of suffix allomorphy. Language and Cognitive Processes, 21, 394-431.

Joanisse, M. F., \& Seidenberg, M. S. (1999). Impairments in verb morphology following brain injury: A connectionist model. Proceedings of the National Academy of Sciences 96, 7592-7597. 
Johnston, R. A., \& Barry, C. (2006). Age-of-acquisition and lexical processing. Visual Cognition, 13, 789845.

Justus, T., Larsen, J., de Morney Davies, P., \& Swick, D. (2008). Interpreting dissociations between regular and irregular past-tense morphology: Evidence from event-related potentials. Cognitive, Affective \& Behavioural Neuroscience, 8(2), 178-194.

MacKay, D., James, L. E., \& Abrams, L. (2002). Cross-language facilitation, repetition blindness, and the relation between language and memory: Replications of Altarriba and Sultano (1996) and support for a new theory. In R. R. Heredia, \& J. Altarriba (Eds.), Bilingual sentence processing (pp. 89-109). Amsterdam: Elsevier.

Maratsos, M. (2000). More overregularizations after all. Journal of Child Language, 28, 32-54.

Marcus, G. F., Brinkmann, U., Clahsen, H., Wiese, R., \& Pinker, S. (1995). German inflection: The exception that proves the rule. Cognitive Psychology, 29, 189-256.

Marslen-Wilson, W. D. (1987). Functional parallelism in spoken word-recognition. Cognition, 25, 71-102.

McClelland, J. L., \& Patterson, K. (2002). Rules or connections in past-tense inflections: what does the evidence rule out? Trends in Cognitive Sciences, 6, 465-472.

Meier, H. (1964). Deutsche Sprachstatistik. Hamburg: Buske.

Meunier, F., \& Marslen-Wilson, W. D. (2004). Regularity and irregularity in French verb inflection. Language and Cognitive Processes, 19(4), 561-580.

Meuter, R. I., \& Allport, A. (1999). Bilingual language switching in naming: Asymmetrical costs of language selection. Journal of Memory and Language, 40(1), 25-40.

Meyer, D. E., \& Schvaneveldt, R. W. (1971). Facilitation in recognizing pairs of words: Evidence of a dependence between retrieval operations. Journal of Experimental Psychology, 90, 227-234.

Mochida, A., \& Harrington, M. (2006). The Yes/No test as a measure of receptive vocabulary knowledge. Language Testing, 23(1), 73-98.

Neubauer, K., \& Clahsen, H. (2009). Decomposition of inflected words in a second language: An experimental study of German participles. Studies in Second Language Acquisition, 31, 403-435.

Oldfield, R. (1971). The assessment and analysis of handedness: The Edinburgh Inventory. Neuropsychologia, 9, 352-360.

Orsolini, M., \& Marslen-Wilson, W. D. (1997). Universals in morphological representation: Evidence from Italian. Language and Cognitive Processes, 12, 1-47.

Pinker, S. (1999). Words and rules: The ingredients of language. New York: Basic Books.

Pinker, S., \& Ullman, M. (2002). The past and future of the past tense. Trends in Cognitive Science, 6, 456-463.

Pfeffer, J. (1964). Grunddeutsch: Basic (spoken) German word list: Grundstufe. Englewood Cliffs, NJ: MIT Press.

Projekt Deutscher Wortschatz (n.d.) Wörterbuch Deutsch-Englisch. URL (accessed 29 March 2011): www. dict.uni-leipzig.de

Ramscar, M. (2002). The role of meaning in inflection: Why the past tense doesn't require a rule. Cognitive Psychology, 45, 45-94.

Rubenstein, H., Garfield, L., \& Millikan, J. A. (1970). Homographic entries in the internal lexicon. Journal of Verbal Learning and Verbal Behavior, 9, 487-494.

Rumelhart, D., \& McClelland, J. L. (1986). On learning the past tenses of English verbs. In J. L. McClelland, D. Rumelhart, \& the PDP Research Group (Eds.), Parallel distributed processing: Explorations in the microstructure of cognition. Vol. 1: Foundations. Englewood Cliffs, NJ: MIT Press.

Segalowitz, N. (2003). Automaticity and second languages. In C. Doughty, \& M. H. Long (Eds.), The handbook of second language acquisition (pp. 382-408). Oxford: Blackwell.

Smolka, E., Rösler, F., \& Wiese, R. (2003). Morphological and semantic priming effects in the processing of German verbs: Evidence from reaction times and event related potentials. In T. Bajo, \& J. Lupianez (Eds.), Proceedings of the Thirteenth Conference of the European Society for Cognitive Psychology ESCoP 2003, Granada, Spain (p. 494). Monachil: Imprenta Santa Rita. 
Smolka, E., Zwitserlood, P., \& Rösler, F. (2007). Stem access in regular and irregular inflection: Evidence from German participles. Journal of Memory and Language, 57(3), 325-347.

Snodgrass, J. G., \& Vanderwart, M. (1980). A standardized set of 260 pictures: Norms for name agreement, image agreement, familiarity, and visual complexity. Journal of Experimental Psychology: Human Learning and Memory, 6(2), 174-215.

Ullman, M. T. (2004). Contributions of neural memory circuits to language: The declarative/procedural model. Cognition, 92(1-2), 231-270.

Ullman, M. T., Corkin, S., Coppola, M., Hickok, M., Growdon, J. H., Koroshetz, W. J., \& Pinker, S. (1997). A neural dissociation within language: Evidence that the mental dictionary is part of declarative memory, and that grammatical rules are processed by the procedural system. Journal of Cognitive Neuroscience, 9(2), 266-276.

Ullman, M. T., Pancheva, R., Love, T., Yee, E., Swinney, D., \& Hickok, G. (2005). Neural correlates of lexicon and grammar: Evidence from the production, reading, and judgment of inflection in aphasia. Brain and Language, 93(2), 185-238.

\section{About the Authors}

Tilo Strobach currently has a post-doctoral position at the Department Psychology at the Ludwig-MaximiliansUniversity Munich, Germany. Prior to that, he finished his PhD at the Humboldt University Berlin, Germany, and did a research visit at the University of California, San Diego. His main research interest is practice and transfer effects of cognitive training (e.g., working memory and dual-task training). The main recent publications are: T. Strobach, R. Liepelt, T. Schubert, \& A. Kiesel (in press). Task switching: effects of practice on switch and mixing costs, Psychological Research, and R. Liepelt, T. Strobach*, P. A. Frensch, \& T. Schubert (in press) Improved inter-task coordination skills after extensive dual-task practice, Quarterly Journal of Experimental Psychology. (*Both first authors contributed equally.)

Ute Schönpflug currently teaches educational psychology at Free University Berlin. She is an adjunct member of the Institute of Cognitive Science in Boulder, Colorado and Associate Editor of the Journal of Crosscultural Psychology. Her recent research focus is on text processing of bilinguals. Her most recent publications in this area are U. Schönpflug, \& F. Klische (2010) Cross- and monolinguistic text-processing in bilingual children, Educational Psychology, 30(7), 849-870, and U. Schönpflug (2010) Erstspracherwerb (First language acquisition) in H.-J. Krumm, C. Fandrych, B. Hufeisen, \& C. Riemer (Eds.), Deutsch als Fremd- und Zweitsprache (German as foreign and second language), pp. 781-792. Berlin: de Gruyter Mouton.

\section{Appendix A}

\section{The PN test}

In the PN test the stimuli were presented on a 16-inch colour screen and controlled by Microsoft Power Point on an IBM-compatible PC. Response latencies of the picture naming were recorded with a microphone connected to the PC and were manually analysed with the sound editing software package Wave Lab. The stimuli covered a size of 1.5 inches on the screen; screen-participant distance was about $60 \mathrm{~cm}$. The presented stimuli were listed at the end of this section and were a sub-sample of 26 pictures from a set of standardized drawings by Snodgrass and Vanderwart (1980). Only those pictures were selected that revealed similar frequency values in English (Francis and Kucera, 1982) and in German (Maier, 1964) and showed a value of more than $86 \%$ of identical naming in the study of Snodgrass and Vanderwart. The presented stimuli were scanned from the paper version of the study. We included the 26 selected pictures in two experimental sets that differ in the order of picture presentations. The presentation of both stimulus sets was equally balanced 
across both groups of participants. The correct picture names in English were taken from Snodgrass and Vanderwart, and the appropriate German names were generated by the authors.

Each trial began with the presentation of the response language indicating whether the presented pictures are named in English or in German in the current trial. Therefore, the word Deutsch (German translation of German) or English was shifted from the bottom to the top of the screen and was presented for $300 \mathrm{~ms}$ in a coloured square. The word German had a yellow square and the word English an orange one. Subsequently, the actual picture stimulus was presented in the centre of the screen. The language indication remained visible during the presentation of the picture stimulus. The start of the presentation was indicated by a sound presented via loudspeakers installed next to the monitor. After a stimulus presentation time of $2000 \mathrm{~ms}$, the next trial started immediately.

Written instructions with a detailed description of the task and one example in each response language (i.e., German and English) not included in the following experimental stimulus set were given to the participants at the beginning of the PN test. After the participant read the instructions, we presented one set of 26 picture stimuli for each participant. The response language within each set was balanced in a random order.

\section{Appendix A Table}

Order of correct picture names in sets I and 2 of the PN test. Numbers in brackets correspond to the numbers of the picture in Snodgrass and Vanderwart (1980).

\begin{tabular}{|c|c|}
\hline Picture set I & Picture set 2 \\
\hline $\begin{array}{l}\text { Scheere (I97) } \\
\text { hanger (II6) } \\
\text { Banane (I6) } \\
\text { Buch (30) } \\
\text { whistle (255) } \\
\text { Schloss (I43) } \\
\text { hand (II5) } \\
\text { Schuh (204) } \\
\text { candle (44) } \\
\text { horse (I2I) } \\
\text { Ohr (83) } \\
\text { snowman (2I0) } \\
\text { Ball (I4) } \\
\text { Kürbis (I8I) } \\
\text { door (76) } \\
\text { balloon (I5) } \\
\text { Leiter (I3I) } \\
\text { Herz (II9) } \\
\text { star (2I7) } \\
\text { Blatt (I33) } \\
\text { bed (22) } \\
\text { flower (9I) } \\
\text { Uhr (60) } \\
\text { Haus (I22) } \\
\text { comb (65) } \\
\text { apple (6) }\end{array}$ & $\begin{array}{l}\text { Herz (II9) } \\
\text { balloon (I5) } \\
\text { flower (9I) } \\
\text { Schuh (204) } \\
\text { snowman (2I0) } \\
\text { Scheere (197) } \\
\text { Leiter (I3I) } \\
\text { whistle (255) } \\
\text { Blatt (I33) } \\
\text { Kürbis (I8I) } \\
\text { door (76) } \\
\text { comb (65) } \\
\text { Uhr (60) } \\
\text { candle (44) } \\
\text { Haus (I22) } \\
\text { hanger (II6) } \\
\text { star (2I7) } \\
\text { Ball (14) } \\
\text { Buch (30) } \\
\text { apple (6) } \\
\text { Ohr (83) } \\
\text { horse (12I) } \\
\text { Banane (16) } \\
\text { Schloss (143) } \\
\text { bed (22) } \\
\text { hand (II5) }\end{array}$ \\
\hline
\end{tabular}




\section{Appendix B}

Words and non-words in LDT on verb participles.

\begin{tabular}{|c|c|c|c|}
\hline $\begin{array}{l}\text { Regular verb } \\
\text { participles }\end{array}$ & Words & Frequency* & Non-words \\
\hline \multirow[t]{10}{*}{ High frequency } & gemacht & 62309 & gemächen \\
\hline & gestellt & 28933 & gestallen \\
\hline & geführt & 25046 & gefuhren \\
\hline & gesagt & 23896 & gesägen \\
\hline & gezeigt & 17589 & geziegen \\
\hline & gehabt & 14042 & gehäben \\
\hline & gelegt & 11093 & geliegen \\
\hline & geöffnet & 9976 & geöffnen \\
\hline & gesichert & 8643 & gesichern \\
\hline & getrennt & 6638 & getrennen \\
\hline \multirow{10}{*}{ Low frequency } & geglüht & 16 & gegluhen \\
\hline & gewacht & 41 & gewächen \\
\hline & gebändigt & 144 & gebandigen \\
\hline & gesträubt & 139 & gestrauben \\
\hline & geschimpft & 270 & geschumpfen \\
\hline & getagt & 289 & getägen \\
\hline & gepachtet & 354 & gepächten \\
\hline & gesäubert & 357 & gesaubern \\
\hline & gestopft & 451 & gestöpfen \\
\hline & gemindert & 418 & gemindern \\
\hline $\begin{array}{l}\text { Irregular verb } \\
\text { participles }\end{array}$ & Words & Frequency & Non-words \\
\hline \multirow[t]{10}{*}{ High frequency } & gefahren & 5005 & gefahrt \\
\hline & getan & 11934 & getut \\
\hline & gedacht & 11896 & gedenkt \\
\hline & geblieben & 12880 & gebleibt \\
\hline & geschrieben & 15118 & geschreibt \\
\hline & gezogen & 12389 & gezieht \\
\hline & gesprochen & 11822 & gesprecht \\
\hline & gesehen & 22667 & geseht \\
\hline & gekommen & 34880 & gekommt \\
\hline & gegeben & 38446 & gegebt \\
\hline \multirow[t]{10}{*}{ Low frequency } & gemahlen & 88 & gemählt \\
\hline & gestunken & 54 & gestinkt \\
\hline & gebogen & 144 & gebiegt \\
\hline & gewunden & 110 & gewindet \\
\hline & geritten & 297 & gereitet \\
\hline & gemocht & 204 & gemögt \\
\hline & gestochen & 495 & gestecht \\
\hline & gegraben & 375 & gegrabt \\
\hline & gehauen & 433 & gehaut \\
\hline & gefressen & 466 & gefresst \\
\hline
\end{tabular}

*Word frequency was determined by the absolute number of occurrences in the selected text corpus of a vocabulary database, www.dict.uni-leipzig.de (Projekt Deutscher Wortschatz, n.d.). 


\section{Appendix C}

Words and non-words in LDT on noun plurals.

\begin{tabular}{|c|c|c|c|}
\hline $\begin{array}{l}\text { Regular noun } \\
\text { plurals }\end{array}$ & Words & Frequency* & Non-words \\
\hline \multirow[t]{10}{*}{ High frequency } & Autos & 18026 & Auter \\
\hline & Details & 6587 & Detaile \\
\hline & Kinos & 3637 & Kinen \\
\hline & Fotos & 5617 & Föter \\
\hline & Tipps & 3454 & Tiper \\
\hline & Büros & 5271 & Büroen \\
\hline & Kameras & 2947 & Kamerer \\
\hline & Hotels & 6739 & Hotelen \\
\hline & Fonds & 7235 & Fönde \\
\hline & Tests & 3500 & Testse \\
\hline \multirow{10}{*}{ Low frequency } & Sofas & 212 & Sofae \\
\hline & Echos & 183 & Echoer \\
\hline & Büfetts & 36 & Bufetten \\
\hline & Filets & 33 & Filete \\
\hline & Kajaks & 34 & Kajaken \\
\hline & Omas & 291 & Ömer \\
\hline & Dias & 105 & Diare \\
\hline & Mottos & 67 & Mottoe \\
\hline & Lassos & 18 & Lässen \\
\hline & Schals & 243 & Schäler \\
\hline $\begin{array}{l}\text { Irregular noun } \\
\text { plurals }\end{array}$ & Words & Frequency & Non-words \\
\hline \multirow[t]{10}{*}{ High frequency } & Blätter & 3479 & Blättse \\
\hline & Bücher & 12133 & Büchs \\
\hline & Häuser & 12316 & Hauss \\
\hline & Türen & 5870 & Türs \\
\hline & Sachen & 4572 & Saches \\
\hline & Gesichter & 3748 & Gesichtse \\
\hline & Herren & 8921 & Herrs \\
\hline & Bräuche & 5408 & Bräuchs \\
\hline & Bäume & 6676 & Bäumse \\
\hline & Märkte & 6860 & Marktse \\
\hline \multirow[t]{10}{*}{ Low frequency } & Löcher & 69 & Löchs \\
\hline & Ränder & 311 & Randse \\
\hline & Gräser & 287 & Grasse \\
\hline & Dielen & 113 & Dieles \\
\hline & Elfen & 159 & Elfes \\
\hline & Lupen & 24 & Lupes \\
\hline & Hüllen & 218 & Hülles \\
\hline & Sümpfe & 181 & Sümpfs \\
\hline & Zünfte & 117 & Zunfts \\
\hline & Stäbe & 6 & Stäbs \\
\hline
\end{tabular}

*Word frequency was determined by the absolute number of occurrences in the selected text corpus of a vocabulary database, www.dict.uni-leipzig.de (Projekt Deutscher Wortschatz, n.d.). 